\title{
Marxismo e pensamento ecológico-ambientalista: uma articulação impossível?
}

\author{
Marxism and ecological-environmental thinking: an impossible link?
}

\section{Luiz Felipe Barros SILVA*}

Resumo: Este texto expõe elementos do método de Marx e Engels que encontram difícil articulação com o pensamento ecológico-ambientalista, enfatizando a crítica subjacente às origens históricas destas diferentes formas de pensar e utilizando sobretudo as obras de John Bellamy Foster e Guillermo Foladori quanto a essa articulação. Ademais, aborda o resgate da perspectiva de Karl Marx por István Mészáros acerca da potencialidade do trabalho diante das diversas demandas políticas e sociais emergentes no capitalismo contemporâneo. O maior empecilho a essa articulação é a pretensa neutralidade do pensamento ecológico-ambientalista em face da contradição entre o capital e o trabalho, algo que deve ser superado pelos novos adeptos que se interessem pela tarefa.

Palavras-chave: Marxismo e Ecologia. Capitalismo e Meio ambiente. Crítica ao ambientalismo.

Abstract: This article exposes elements of Marx's and Engel's methodologies that have a problematic connection with an ecologic-environmental perspective and, mainly using the works of John Bellamy Foster's and Guillermo Foladori's on this link, emphasises the subjacent review of the historical origins of these different ways of thinking. Furthermore, it deals with the recovery of Marx's perspective by Îstvan Mészáros regarding the potential of labour in countering the various political and social demands emerging in contemporary capitalism. The greatest obstacle to this link is the pretentious neutrality of ecologic-environmental thinking in the face of the contradictions between capital and labour, something that must be overcome by the new specialists interested in this task.

Key words: Marxism and ecology. Capitalism and Environment. Critique of Environmentalism.

Submetido em: 30/4/2018. Revisado em: 26/7/2018. Aceito em: 9/8/2018.

\section{INTRODUÇÃO}

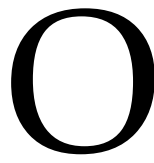

marxismo é a teoria social mais conhecida que se opõe ao modo de produção historicamente vigente, o capitalista. O legado de Karl Marx e de seus seguidores fazse perceber nos diversos campos da sociedade: político, científico, artístico etc. Sua importância histórica, embora não seja consenso absoluto na sociedade em geral, provoca a existência tanto de seguidores quanto de opositores fiéis, o que demonstra a importância de seu legado. Quanto mais se aprofunda a crise do capital e se explicita a ausência de alternativas em seu próprio interior para tirá-lo do buraco, mais os contornos teóricos de Marx tornam-se plenos de sentido.

\footnotetext{
${ }^{*}$ Geógrafo. Mestrando em Serviço Social pela Universidade Federal de Alagoas. Campus A. C. Simões. Av. Lourival Melo Mota, S/N, Tabuleiro do Martins, Maceió (AL), CEP.: 57072 -90o. E-mail: <luizfelipebarross@gmail.com>. ORC ID: <https://orcid.org/oooo-0o03-3836-3360>.
} 
Por outro lado, a ecologia e o pensamento ambientalista podem ser sintetizados em uma forma de pensar que procura estudar a inter-relação homem-meio do ponto de vista da preservação do meio natural, considerando os impactos humanos em suas mais variadas formas de relação com a natureza, como causa dos crescentes desequilíbrios naturais no planeta. Sua síntese teórica moderna deve-se originariamente a Ernst Haeckel, no século XIX, ainda que seu desenvolvimento como um importante campo da ciência ocorra, sobretudo, na segunda metade do século XX. Com o crescimento vertiginoso da degradação do meio ambiente global, esta forma de pensar ganha corpo, sendo incorporada aos diversos segmentos sociais.

Muitos teóricos de ambas as vertentes tentaram articular estas formas de pensar em torno da possibilidade de superar o modo de produção capitalista e com isso, reverter a destruição do meio ambiente. Entretanto, seus desenvolvimentos particulares os levaram para caminhos repletos de problemas internos, dificultando ou tornando periférica a realização de tal articulação. Muitos realizaram efetivamente grandes avanços em seus específicos campos de estudo, considerando uma dada articulação possível. Certamente, desde a emergência do problema ambiental sob o modo de produção capitalista em meados do século XX, a articulação entre marxismo e ecologia é proposta, originando diversas vertentes de pensamento tanto no interior de um quanto no outro campo, com práticas sociopolíticas também diversas.

Neste texto, desenvolveremos algumas das características específicas do pensamento ecológico-ambientalista e marxista que levam a uma situação aparentemente insolúvel do ponto de vista teórico, elaborando um passo no caminho que visa traçar um panorama explicativo da difícil articulação destas formas de pensar de raízes tão distintas. Recorreremos a alguns autores que nos parecem possuir um aguçado senso crítico, ao ponto de enfrentarem as contradições inerentes a essa articulação, sobretudo Guillermo Foladori e John Bellamy Foster. Ao fim, incorporaremos uma ressalva crítica às políticas ambientalistas, com um fomento mais radicalmente marxista ancorado em István Mészáros, no resgate que faz da obra de Marx quanto ao papel da centralidade do trabalho, num momento em que tantas demandas políticas parciais emergem.

\section{O MÉTODO MARXIANO E A INTERPRETAÇÃO ECOLÓGICO-AMBIENTALISTA}

Segundo Foladori, nem Marx nem Engels escreveram sua “[...] concepção materialista da história [...]" (FOLADORI, 1990, p. 9) de forma sistemática e didática, mas “[...] a aplicaram em todas as suas análises [...]” (FOLADORI, 1990, p. 9), pois que ela está inscrita no próprio método dos). Seus princípios filosóficos estão, portanto, inseridos na forma de os autores pesquisarem e agirem no mundo. E, também, sintetizados em alguns poucos parágrafos de alguns de seus escritos.

Em primeiro lugar, convém destacar uma primeira grande superação filosófica de Marx e Engels, ainda na juventude. Os autores escreveram em $A$ ideologia alemã que,

A produção das ideias, das representações, da consciência está em princípio diretamente entrelaçada com a atividade material e o intercâmbio material dos homens, linguagem da vida real. O representar, o pensar, o intercâmbio espiritual dos ho- 
mens aparece aqui ainda como direta exsudação do seu comportamento material (MARX; ENGELS, 2009, p. 31).

Em resumo, afirmam os autores que "[...] não é a consciência que determina a vida, mas a vida que determina a consciência” (MARX; ENGELS, 2009, p. 31-32).

Tal consideração de método acompanhou os autores por toda a vida, daí ser imprescindível que, para o marxismo, a dimensão material da realidade concreta seja encarada como tal, já que é a própria realidade em termos objetivos que determina as ideias e representações que os homens têm do mundo material, de acordo com Marx e Engels. As formas de pensar que acreditam poder resolver as contradições humanas apenas pelo desenvolvimento no âmbito da própria consciência acham-se em profunda divergência com o materialismo histórico, com base no que foi formulado pelo próprio Marx, a denominada teoria marxiana.

Para Marx, as categorias sociais não são passíveis de ser modificadas como convém pelo sujeito que as analisa, pois estas “[...] exprimem formas de vida, determinações da existência” (MARX, 2008, p. 267). Devem, portanto, ser encaradas como realidade objetiva.

Segundo Netto, sintetizando o método marxiano,

O conhecimento teórico é o conhecimento do objeto - de sua estrutura e dinâmica tal como ele é em si mesmo, na sua existência real e efetiva, independentemente dos desejos, das aspirações e das representações do pesquisador. A teoria é, para Marx, a reprodução ideal do movimento real do objeto pelo sujeito que pesquisa: pela teoria, o sujeito reproduz em seu pensamento a estrutura e a dinâmica do objeto que pesquisa. E esta reprodução (que constitui propriamente o conhecimento teórico) será tanto mais correta e verdadeira quanto mais fiel o sujeito for ao objeto. (NETTO, 2011, p. 20-21).

O enfrentamento das contradições internas da sociedade burguesa, para Marx e Engels, implicava desde muito cedo uma superação prática, ainda que a teoria tivesse um grande papel a cumprir na iluminação desse caminho, como é claramente visível na tese à Feuerbach de número 9: "A vida social é essencialmente prática. Todos os mistérios que induzem a teoria ao misticismo encontram sua solução racional na prática humana” (MARX; ENGELS, 20o9, p. 125).

Por conta dessas questões, Marx e Engels concluem em suas formulações, a partir da análise da realidade objetiva, pela necessidade de transformar o mundo em termos práticos. Assim, a revolução aparece como um meio político historicamente possível e eficaz para alavancar a humanidade à sua existência livre das classes sociais e da exploração do homem pelo homem.

Segundo Netto, um dos pressupostos mais essenciais do método marxiano é o fato de se vincular a um "[...] projeto revolucionário" (NETTO, 2011, p. 10). Esta característica implica a fusão prática entre a teoria - na exigência de uma análise da realidade que corresponda ao real objetivamente existente - e a política, na medida em que a superação do metabolismo social do capital não pode prescindir da tomada do poder propriamente dito. 
Para Marx e Engels, a superação do antagonismo social, da miséria e da penúria dos trabalhadores tinha de ser obra dos próprios trabalhadores, ao realizarem esta revolução e aplicarem o seu projeto de sociedade de produtores livres, isto é, criando uma forma autoorganizada de produzir. Esta seria, para eles, a única forma de subverter o domínio do capital com eficácia.

Aqui podemos sublinhar dois elementos para destacar como características do método marxiano de difícil conciliação com o pensamento ecológico-ambientalista: na teoria, o ponto de vista do objeto, e na prática política, a vinculação a um projeto revolucionário.

Muitas vezes o método de Marx e Engels foi equivocadamente posto ao lado de pensadores entusiastas do capitalismo por alguns ecologistas, tachando-os de prometeístas ${ }^{1}$, deterministas ou economicistas - um modo de denunciá-los como insensíveis para com a natureza. Isto permitiu uma aparente refutação de Marx e Engels no campo da ecologia por muito tempo, e até hoje é reproduzido de alguma forma.

Um exemplo interessante de uma interpretação equivocada do pensamento marxiano transparece na obra de Ponting (1995). Seu conhecimento sobre Marx e Engels lhe permitiu igualá-los a positivistas como August Comte. Ele os coloca no bojo dos intelectuais europeus, junto com o maior representante do positivismo - a corrente filosófica que foi a voz teórica da justificação da vitória da burguesia. Como se Marx fosse partidário do capitalismo pela sua avaliação positiva acerca do desenvolvimento das forças produtivas, tal como os positivistas em relação aos modos de produção anteriores ${ }^{2}$, sugerindo, assim, que Marx seria herdeiro de uma influência judaico-cristã de dominação da natureza.

Segundo Ponting, essas “[...] primitivas influências clássicas e judaicas, foram incorporadas quase que despercebidamente, no padrão geral das crenças que formavam os fundamentos da visão europeia do mundo [...]"(PONTING, 1995, p. 251-2), incluindo o pensamento de Marx. Ponting pensa que "[...] os seres humanos eram vistos [por esse pensamento europeu que formou o padrão geral das crenças] como separados e superiores a um mundo natural, que tinham o direito de explorar como bem lhes aprouvesse" (PONTING, 1995, p. 251-252).

Na visão de Ponting (1995), a questão definitiva não é a relação que o ser humano, sob suas intricadas relações de classe, estabelece com a natureza e com a própria espécie que determina a destruição do mundo natural, mas uma questão meramente de consciência individual. Ele condena Marx apenas porque este não cedeu às ideias românticas da negação, pela via

\footnotetext{
1 Trata-se de uma acusação por parte de teóricos que tentaram deslegitimar Marx de que este aplicaria uma espécie de mecanicismo, na medida em que saldou, assim como Bacon, o mito de Prometeu acorrentado do grego Ésquilo, como uma figuração representativa do significado do materialismo e da ciência para a hum anidade em sua evolução histórica. Para estes críticos, Marx teria abraçado integralmente a visão iluminista de uma superioridade absoluta, mecânica, do homem sobre (e contra) a natureza. Mas, para Foster, esta acus ação não passa de "[...] um modo circular de rotular a obra de Marx e o marxismo como um todo como uma versão ex trema do modernismo [...]" (FOSTER, 2005, p. 191), ou seja, de pintar um Marx adorador das faç anhas do capitalismo, em vez de um crítico ferrenho deste metabolismo social.

2 Esta avaliação do marxismo é retirada da primeira parte do Manifesto do Partido Comunista, em que os autores destacam e reconhecem a vitória da burguesia como positiva para a humanidade na primeira parte do texto, descartando toda a crítica subsequente, onde o restante da a nálise torna lúcida a insuficiência da burguesia em dar conta das demandas do trabalho, já que subsiste perpetuamente a partir da sua exploração - o que exige a superação da sociedade burguesa como um todo.
}

Argum., Vitória, v. 10, n. 2, p. 161-173, maio/ago. 2018. 
da consciência, do desenvolvimento objetivo do capital, mas reconheceu o caráter vitorioso da burguesia, que não triunfou devido a um mero insight de consciência, senão pelo poder dos meios de produção na forma de capital que detinham, sobretudo ao assumir o completo comando sobre o trabalho.

Para o autor, Marx e Engels seriam apenas pensadores que escolheram conscientemente orientar-se segundo o princípio de que os seres humanos poderiam explorar ilimitadamente os recursos da natureza. Assim, seriam partidários de uma inevitabilidade do progresso capitalista.

Para fundamentar essa complicada afirmação, o autor utiliza a passagem dos Manuscritos Econômico-Filosóficos de 1844, em que Marx afirma que a natureza é o objeto dos seres humanos, um instrumento para a realização do seu metabolismo.

Para Ponting (1995), Marx teria adotado

Muitas crenças da economia clássica e do pensamento ocidental anterior, na maneira como trataram os recursos e o meio ambiente, levando, em muitos casos, essas visões a extremos que não encontraram paralelo em qualquer outro lugar (PONTING, 1995, p. 260-261).

Ponting vai ainda mais longe, ao dizer que a meta mais importante de Marx, Engels e Lenin "[...] seria elevar o proletariado ao nível de consumo adquirido pela burguesia da Europa do século XIX" (PONTING, 1995, p. 260-261).

Aqui o autor revela um grande reducionismo analítico do que pensavam Marx, Engels e Lênin, interpretando o oposto da tese de superação do capital através de uma revolução social da classe que é antagonista do capital por excelência, o proletariado, e equiparando a possibilidade e a necessidade histórica da emancipação da humanidade que Marx, Engels e Lenin acreditavam à elevação do nível de consumo do proletariado.

De outra maneira, um autor mais recente, Marques (2015), elaborou uma obra de magnitude sobre os desastres ambientais contemporâneos mais sérios, um inventário muito interessante sobre o estágio a que chegamos em diversas formas de destruição do meio natural. Citando dados e relatório oficiais, ele realiza um apanhado completo e rigoroso do ponto de vista do diagnóstico, mas acaba por propor soluções conciliadoras com o capital, propondo apenas ajustes técnicos e afirmando a urgência absoluta de políticas radicalmente ecológicas, sem reconhecer o capital como causa econômica dos desastres ambientais contemporâneos.

Ele procura descartar as ideias marxianas. Afirma que parte das concepções de esquerda “[...] que não romperam com suas raízes históricas [...] (MARQUES, 2015, p. 19), ou seja, que ainda permanecem ancoradas ao fundamento de Marx, herdou deste uma concepção de história "[...] centrada no protagonismo das forças produtivas e na quase identificação entre o desenvolvimento destas e o 'progresso' histórico”' (MARQUES, 2015, p. 19). Para defender esta tese, o autor lança mão de uma única passagem de Marx - a qual, embora seja interessante, foi mal interpretada, para não dizer deturpada - do seu Prefácio da Contribuição à Crítica da Economia Política, de 1859:

Argum., Vitória, v. 10, n. 2, p. 161-173, maio/ago. 2018. 
Em uma certa etapa de seu desenvolvimento, as forças produtivas materiais da sociedade entram em contradição com as relações de produção existentes, ou, o que não é mais que sua expressão jurídica, com as relações de propriedade no seio das quais se haviam desenvolvido até então. De formas evolutivas das forças produtivas que eram, essas relações transformam-se em seus entraves. Inaugura-se então uma época de revolução social (MARX, 20o8, p. 48-51).

Para refutar Marx, Marques (2015) diz que o conteúdo desta passagem é uma espécie de “[...] mecânica da história [...]" (MARQUES, 2015, p. 20); prova disso seria que, no século XX,

As relações de produção capitalistas não entravaram (muito pelo contrário) o desenvolvimento das forças produtivas e que, justamente por isso, o traço distintivo do capitalismo no século XXI é a tendência ao colapso ambiental. (MARQUES, 2015, p. 19-20).

Neste ponto, bem parecido com Ponting (1995), apresenta uma espécie de prova irrefutável evidente de que Marx estaria ultrapassado. Isso serve para o autor defender uma posição que se expressa politicamente exatamente ao contrário do que Marx propunha quanto à última categoria mencionada na passagem: a revolução social. Diz ele que,

Diante dessa tendência definidora de nosso século, conservar o que resta da biosfera tornou-se a condição primeira de possibilidade não apenas de avanços sociais [...], mas da simples manutenção de qualquer sociedade organizada (MARQUES, 2015, p. 19-20).

Ao invés da revolução social do trabalho contra o capital, o autor prefere a crença em uma via de aprovação de políticas radicais de proteção do meio ambiente, pressupondo que esse antagonismo não é a questão central. Por isso, para ele, o pensamento marxiano teria se tornado anacrônico para compreender a realidade social, e a esquerda que permanece ancorada em seus fundamentos não consegue compreender o “imperativo ecológico". Sua proposição tem como intenção uma adesão generalizada das pessoas ao imperativo ético pró-natureza como forma de superar o sistema social do capital, uma espera pela sensibilização universal para legitimar as medidas políticas, sem focar na superação econômica do capital.

É bastante clara a superficialidade da análise social presente em seu pensamento. O problema central "da esquerda", para ele, foi ter dissociado a “[...] agenda social da agenda ecológica” [...] (MARQUES, 2015, p. 20). Marques chega a conclusões muito parecidas com as de Ponting quanto à determinação da consciência, quando identifica o problema a um “[...] obstáculo cognitivo ou bloqueio mental comum à quase totalidade do espectro ideológico [...]" (MARQUES, 2015, p. 20), e lista, em seguida, alguns “[...] mecanismos psicológicos [...]” que tendem a "[...] dificultar uma tomada de consciência da gravidade das crises ambientais" (MARQUES, 2015, p. 20).

Parece-nos precipitada a conclusão de que Marx e Engels partiriam de uma espécie de "aceitação do progresso" como uma aceitação do capitalismo, e que, por isso, a natureza não teria significado algum para eles (PONTING, 1995). Ou ainda, a de que o pensamento marxiano identificaria o progresso humano ao progresso das forças produtivas do capital (a técnica) e, por isso, os autores seriam anacrônicos para compreender a sociedade contemporânea (MARQUES, 2015).

Argum., Vitória, v. 10, n. 2, p. 161-173, maio/ago. 2018. 
Aqui citaremos alguns elementos presentes na análise de John Bellamy Foster, em que está clara a sensibilidade de Marx para com a relação do ser humano com a natureza que era inaugurada com a era do capital e, sobretudo, com o surgimento da grande indústria. $\mathrm{O}$ primeiro é que a origem do materialismo de Marx diz muito sobre os insights ecológicos presentes em sua teoria. E o segundo, a incorporação do conceito de metabolismo social do químico agrícola Justus Von Liebig, demonstra sua preocupação em expressar teoricamente tanto a relação que ocorre entre os próprios homens, como entre os homens e a natureza.

Acham-se bem expostas por Foster (2005), em A ecologia de Marx, as origens materialistas do método de Marx e Engels. Sua pesquisa faz uma interseção das influências filosóficas de Marx e de Darwin, asseverando que o ponto em que elas coincidem guarda uma profunda conexão com o entendimento da relação do ser humano com o mundo natural.

O materialismo do grego Epicuro é o fio condutor destas diferentes abordagens, tanto da de Darwin, por exemplo - centrada em entender as leis gerais que determinam a evolução das espécies - quanto da de Marx - que procurou estudar a origem do pensamento materialista na Antiguidade, já no seu doutorado 3 .

Foster afirma que o “[...] princípio da conservação [...]” de Epicuro tinha uma “[...] tendência a uma visão de mundo ecológica” (FOSTER, 2005, p. 61). Ele “[...] aludiu à poluição atmosférica causada pela mineração, à redução das colheitas pela degradação do solo e ao desaparecimento de florestas; além de argumentar que os seres humanos não eram radicalmente distintos dos animais" (FOSTER, 2005, p. 61).

Por conta desta tendência, o grego influenciou materialistas modernos de tão distintas áreas, a exemplo de Marx, Darwin e até mesmo Justus Von Liebig, responsável pelo uso do conceito de metabolismo para entender os organismos sociais na Biologia, algo que Marx incorporou a partir de 1851, quando entra em contato com sua teoria, utilizando-o até o fim de sua vida.

Liebig identificou que há relação entre o esgotamento do solo e a "[...] poluição das cidades com esgoto humano e animal [...]" (FOSTER, 2005, p. 217-8), contribuindo para a conclusão de Marx acerca da iminente crise agrícola das economias avançadas, e ainda mais profundamente, para a sua incorporação de um conceito fundamental, o de metabolismo (stoffwechsel), que implica uma “[...] 'troca material' subjacente à noção dos processos estruturados de crescimento e decadência biológicos” (FOSTER, 2005, p. 221). Marx passou a usar este conceito durante o resto de sua vida, e segundo Foster, ele é visível em muitas de suas obras de maturidade, tanto com um "[...] significado ecológico específico quanto com um significado social mais amplo” (FOSTER, 2005, p. 222-223).

\footnotetext{
3 Marx escreveu sua tese de doutoramento acerca da diferença das concepções materialistas de Demócrito e Epicuro, preferindo o materialismo deste último, pois possuía mais elementos da realidade verificáveis, sem mecanicismos e determinismos. Ao contrário de Epicuro, Demócrito considerava a verdade últi ma sobre o átomo incognoscível e desconsiderava o acaso como um elemento importante da realidade material. Foi Marx quem destacou diferençafundamental entre os dois, estabelecendo um ponto de ruptura com outros materialistas que preferiam Demócrito, como Hegel, ou Bacon, que criticou Epicuro pelo mesmo motivo que fez Marx preferi-lo a Demócrito (FOSTER, 2005).
} 
Segundo Foster, “[...] O conceito de metabolismo [...] permitiu que ele expressasse a relação humana com a natureza como uma relação que abrangia tanto as 'condições impostas pela natureza', quanto a capacidade dos seres humanos de afetar este processo” (FOSTER, 2005, p. 223).

De acordo com Foster, parece mais sensato afirmar que o pensamento marxista não desco nsiderou a natureza de nenhuma forma, mas tentou tratá-la com o seu próprio estatuto ontológico sem, entretanto, desconsiderar as formas particulares da materialidade social e a exigência de uma revolução social do trabalho contra o capital e dos trabalhadores contra a burguesia.

\section{A CRÍTICA MARXISTA AO PENSAMENTO ECOLÓGICO-AMBIENTALISTA}

A Ecologia é um ramo das ciências biológicas definido usualmente como "[...] o estudo das relações dos organismos ou grupos de organismos com o seu ambiente, ou a ciência das inter-relações que ligam os organismos vivos ao seu ambiente" (ODUM, 2001, p. 4).

Apesar de existirem antecedentes de estudos semelhantes, o termo ecologia foi cunhado pela primeira vez por Ernst Haeckel em 1869, dois anos após O capital de Marx e dez após A origem das espécies de Darwin. Entretanto, seu desenvolvimento como um importante campo da ciência ocorrerá principalmente no século XX. Uma definição mais moderna de Ecologia a designa como "[...] o estudo da estrutura e funcionamento da natureza, considerando que a humanidade é parte dela" (ODUM, 2001, p. 4).

Não há, de fato, nenhum problema quanto ao estudo dessa cadeia de processos de que tenta se ocupar a Ecologia. A questão, entretanto, é outra. A Ecologia passa a se tornar polêmica ao adentrar a esfera da política, implicando entendê-la como uma teoria impulsionadora da construção de uma realidade metabólica diferenciada do homem com a natureza, sem buscar compreender as possibilidades internas de como isso acontece nas sociedades humanas e as circunstâncias sob as quais teriam de agir.

Isto significa que ela procura derivar da análise que faz da inter-relação das espécies e delas com o seu meio - incluindo a sociedade como uma destas espécies - suas proposições políticas e sociais. Um dos maiores problemas está em tomarem como premissa teórica uma humanidade tomada em certa homogeneidade e sua interação com o meio natural. A ausência de uma análise histórico-social rigorosa confere à Ecologia uma análise social profundamente especulativa, carente do conhecimento dos conflitos sociais reais, da contradição entre capital e trabalho, da impossibilidade de o próprio sistema do capital absorver integralmente as demandas da preservação do meio ambiente. Tampouco é possível, sem uma análise sócio-histórica, compreender as diversas formas de práxis que a humanidade já estabeleceu e ainda estabelece com a natureza. Ainda que muito tolhidas pela mercantilização exacerba da de um capitalismo em crise, é possível observar formas de interação com a natureza em algumas sociedades humanas que tentam excluir-se dos circuitos capitalistas.

No presente texto, nos referiremos mais a uma determinada parcela do movimento ecológico-ambientalista, pois este possui disputas teóricas e políticas em diversas vias interpretativas, nuances que também seriam abarcadas no caso de uma análise mais profunda.

Argum., Vitória, v. 10, n. 2, p. 161-173, maio/ago. 2018. 
Para analisar as diversas abordagens, é esclarecedora a tipologia de Guillermo Foladori, que elencou pontos em comum entre as diferentes interpretações, visando traçar linhas gerais que se assemelham e se conectam.

Um destes é o ponto de partida ético, que opõe os antropocentristas aos ecocentristas. O pensamento antropocentrista seria aquele que, de alguma forma, prioriza os interesses dos homens sobre os da natureza, ou os considera "[...] como diretriz do relacionamento do homem com o meio ambiente" (FOLADORI, 2005, p. 4).

Este ponto de vista pode ser subdividido em variados pensamentos radicalmente diferentes entre si, incluindo o pensamento religioso judaico-cristão e a tradição filosófica iluminista. Esta corresponde a uma maré materialista que ocorreu no fim do feudalismo, da qual, de certa forma, Marx e Engels também foram partícipes, ao absorverem a herança teórica dessa época de grandes descobertas para a autocompreensão humana e natural. Contudo, é preciso enfatizar que eles desenvolveram uma maneira inteiramente nova e única de pensar a materialidade socionatural, intentando transcender quaisquer dualismos ou falsas oposições filosóficas.

Já o pensamento ecocentrista tem como pressuposto um ponto de partida de que há interesses intrínsecos à natureza, e já que os objetos naturais não podem denunciá-los, seria necessário “[...] outorgar à natureza valores intrínsecos, externos ao ser humano” (FOLADORI, 2005, p. 11). Tem base em um “[...] ponto de partida ético [...]”, de forma que “[...] essa ética eco, ou biocentrista, deveria orientar o comportamento humano” (FOLADORI, 2005, p. 11).

Essa busca de códigos éticos na natureza externa ao ser humano provém de uma vi-
são da natureza e da sociedade humana como esferas separadas. A natureza é enca-
rada como aquilo que existe sem a intervenção humana. Esta concepção distingue o
natural do artificial como dois opostos. A ação e os produtos da sociedade humana
são artificiais, opostos à natureza. Isso induz a um critério de avaliação ante a pro-
blemática ambiental. O natural seria o bom, e o artificial seria o mau (FOLADORI,
2005, p. 11).

Esta concepção procura simplificar, em dois conceitos valorativos, algo que ocorre na realidade de uma maneira muito mais complexa do que um dualismo. Poderíamos mencionar que essa romantização do mundo natural, ao atribuir um valor (humano) de bondade à objetividade natural, não compreende que o próprio metabolismo humano é objetivamente a ineliminável transformação social de sua própria base natural. É, ao mesmo tempo, natureza e natureza transformada.

A concepção ecocentrista entende que a humanidade atuaria como um bloco diante da natureza externa, do seu meio, não reconhecendo antagonismos inerentes à prática social. Para os ecocentristas, a causa dos problemas ambientais seria

Uma ideologia ou uma técnica, mas sempre da sociedade em bloco contra o meio. Para analisar o comportamento humano diante do meio ambiente, não têm maior importância as contradições ou diferenças existentes no seio da sociedade humana. O problema é técnico, não social (FOLADORI, 2005, p. 17).

Argum., Vitória, v. 10, n. 2, p. 161-173, maio/ago. 2018. 
Já para o marxismo, sua base filosófica e pressupostos são outros. Foladori o incorpora à tradição antropocentrista em sua tipologia, apesar de concordar com o fato de que o marxismo parte de uma base filosófica incompatível com um pensamento dualista desse tipo.

A diferença do marxismo

[...] está em que, primeiro, a natureza inclui a sociedade humana, não sendo algo por fora como nas concepções ecocentrista e tecnocentrista. Nesse sentido, a distinção entre 'natural' e 'artificial', que é a base das posições ecocentristas e antropocentristas, não pode servir como critério para a ação (FOLADORI, 2005, p. 18).

O marxismo também não compreende a sociedade humana como se atuasse em um bloco indiviso diante do mundo natural, mas assevera que há distintas classes sociais em disputa, segmentos que possuem uma prática social diferenciada no uso que fazem da natureza e, consequentemente, nos impactos que provocam sobre a natureza. Há, contudo, uma cisão que é ainda mais fundamental no interior do organismo social capitalista: a que divide a humanidade entre capitalistas e trabalhadores, algo que diferencia a abordagem marxiana de todas as outras quanto ao seu pensamento ambiental.

O marxismo, sob esse ponto de vista, é a teoria que deve dar voz ao trabalho, à classe que realiza a transformação metabólica humana, à classe que produz toda a riqueza da humanidade. Tal formulação teórica armaria a humanidade para a tarefa prática de ação contra essa força social que nos domina. Para o marxismo, esta seria a única maneira de superar a cisã o que ocorre no interior da humanidade, com a exploração do homem pelo homem, e também a cisão que o capital inaugurou na história humana, com a ruptura nos ciclos globais da natureza, oriunda do processo de mercantilização dos recursos naturais globais.

Já o pensamento ecológico-ambientalista retira da constatação dos problemas ambientais a necessidade urgente e absoluta de as pessoas aderirem a um ponto de vista ético ecocêntrico, mas como não faz a crítica à sociedade do capital para buscar as alternativas eficazes de transformação social, precisa utilizar os próprios meios operados pela sociedade burguesa para propor as mudanças desejadas. Isso significa cair na circularidade do mero reconhecimento formal das necessidades candentes, sem a correspondente diminuição ou eliminação das práticas destrutivas, ajustes meramente técnicos que não se traduzem em mudança efetiva.

\section{INDO ALÉM DA POLÍTICA ECOLÓGICO-AMBIENTALISTA: A CENTRALIDADE DO TRABALHO}

As políticas ambientalistas que pressupõem uma possibilidade de o capital alterar sua própria natureza através de uma espécie de tomada de consciência dos seus aspectos mais destrutivos são natimortas e estão fadadas à frustração, como bem demonstram os resultados das últimas décadas em que esta questão foi posta inúmeras vezes, para não deixar dúvidas, pelos ambientalistas, simbolizadas pelas grandes conferências globais como a Rio-92, Rio+10 e Rio+20. Mészáros, analisando o primeiro destes "grandes encontros festivos", menciona que as políticas resolutivas então propostas "[...] só são usadas como álibi para que tudo con- 
tinue como antes, sem que nada se faça para enfrentar o desafio, enquanto se finge 'cumprir as obrigações assumidas"' (MÉSZÁROS, 2011, p. 223, nota 8).

Os obstáculos permanecem e se repõem sempre de forma piorada com o desenvolvimento recente do capital, tanto de um ponto de vista das destruições da natureza, quanto do ponto de vista da destruição de vidas humanas. A nosso ver, de acordo com o legado marxiano, estes problemas possuem uma causa comum e requerem a eliminação material da relaçãocapital como regente da produção que destrói os processos naturais através da dominação sobre o trabalho e a natureza, sua base biológica e social de sustentação; e a implementação de outra relação material, superior, que a substitua.

Nesse sentido, para Mészáros (2011):

Os obstáculos são comuns ao trabalho e aos movimentos de 'questão única' [...]. Sob o domínio do capital, somente se podem legitimar as demandas integradas. O ambientalismo, por sua própria natureza [...], é não integrável. Consequentemente, nenhuma causa desse gênero desaparecerá, não importa quantos tropeços e derrotas politicamente organizadas dos movimentos de 'questão única' tenham de sofrer no futuro previsível (MÉSZÁROS, 2011, p. 95).

O capital em si, para Mészáros (2011) e de acordo com Marx, “[...] é absolutamente incapaz de se impor limites, não importando as consequências, nem mesmo a eliminação total da humanidade" (MÉSZÁROS, 2011, p.251). Nem sequer isso seria capaz de fazer com que os responsáveis pela manutenção de seu mecanismo tomassem consciência do problema ambiental. O capital deve ignorar a natureza dos problemas, até mesmo quando estes já se encontram em sua “[...] escala proibitiva [...]” (MÉSZÁROS, 2011, p. 254), pois,

É da natureza do capital não reconhecer qualquer medida de restrição, não importando o peso das implicações materiais dos obstáculos a enfrentar, nem a urgência relativa (chegando à emergência extrema) em relação a sua escala temporal. A própria ideia de restrição é sinônimo de crise, no quadro conceitual do sistema do capital. A degradação da natureza ou a dor da devastação social não têm qualquer significado para seu sistema de controle sociometabólico, em relação ao imperativo absoluto de autorreprodução numa escala cada vez maior (MÉSZÁROS, 2011, p. 253).

Ainda segundo Mészáros: “As pessoas preocupadas com o ambiente perderão a batalha pela racionalidade abrangente e restrição legítima da economia antes mesmo de ela começar, se sua meta não envolver a mudança radical dos parâmetros estruturais do próprio sistema do capital" (MÉSZÁROS, 2011, p. 263).

Não destruir os processos naturais e explorar o trabalho em escala crescente é um privilégio de que o capital não pode gozar, pois viceja nestas contradições. E as derrotas para os que não conseguirem identificar a causa capitalista tendem a ser fatais para estes movimentos políticos. Não obstante, a relação-capital permanecerá aniquilando as nossas condições de reprodução metabólica social, até que percorramos o caminho necessário para criar uma nova relação com base no trabalho associado, de que falou Marx, que consiste em uma forma radicalmente diferente de relação com a natureza, originando outra racionalidade nas pessoas envolvidas. 
Nesse sentido, é necessário entender os limites do próprio capital, tomado em seu aspecto objetivo, e da ação política restrita a alguma demanda social isolada e apartada do trabalho. A potencialidade do trabalho para a superação desta ordem metabólica social é algo profundamente diferente das demandas parciais, pois ele é o único portador material da condição de eliminar os antagonismos sociais, exatamente através da sua generalização.

Mészáros resgata esta discussão e menciona que Marx buscou transcender a parcialidade crônica da política enquanto tal, a canalização das demandas sociais parciais todas para o interior do Estado. Isso permitiu enxergar o trabalho como a única parcialidade que tem a potência de se tornar universal; apesar de ainda ser parcialidade, é uma "[...] parcialidade que necessariamente se autoextingue” (MÉSZÁROS, 2011, p. 567-8). Ela, diferentemente de outras parcialidades, "[...] não pode ser convertida em uma condição de domínio exclusivo da sociedade” (MÉSZÁROS, 2011, p. 568). Isto significa que “[...] para 'dominar', o proletariado deve generalizar sua própria condição de existência: a saber, a incapacidade de dominar, como uma parcialidade, a expensas de outros grupos e classes" (MÉSZÁROS, 2011, p. 568). Assim, o trabalho mais fundamental para o proletariado possui como medida de sucesso a realização de uma revolução social que é, em si, “[...] a generalização de um modo de existência totalmente incompatível com o domínio de classe” (MÉSZÁROS, 2011, p. 568).

\section{CONCLUSÃO}

Eduardo Galeano comenta que na situação contemporânea do debate ambiental, há uma grande mentira propalada pela mídia mundial, a de que "[...] entre o capital e o trabalho, a ecologia é neutra” (GALEANO, 2011, não paginado). Todavia, diz ele, na realidade, “[...] a ecologia neutra, que mais se parece com a jardinagem, torna-se cúmplice da injustiça de um mundo onde a comida sadia, a água limpa, o ar puro e o silêncio não são direitos de todos, mas sim privilégios dos poucos que podem pagar por eles" (GALEANO, 2011, não paginado).

Certamente, o pensamento ecológico-ambientalista pode compreender a sociedade sob o ponto de vista do seu antagonismo social fundamental do capital contra o trabalho. Este caminho nunca estará bloqueado, mas há de saber que jamais estará neutro diante da luta de classes; esta parece ser a premissa mais urgente de ser transcendida. A perspectiva do pesquisador, velada ou explícita, ou é a da adesão ao ponto de vista do capital, da reprodução social tal como está, tentando apenas atenuar seus exageros destrutivos; ou a perspectiva da adesão ao trabalho, à construção de uma alternativa social revolucionária e igualitária como a melhor forma de resolver as práticas metabólicas destrutivas da humanidade.

É fato que uma parcela do movimento ecológico-ambientalista reproduz uma tradição antiMarx, mas isto nada diz sobre o futuro, com o provável crescimento das degradações ambientais concomitantes com o acirramento da crise do capital em seu caráter global. Com isso Marx encontra cada vez solo mais fértil para retornar, como a hidra de Lerna da mitologia grega, que a regenera sempre que tem uma de suas cabeças cortadas.

As mudanças históricas que os novos adeptos do pensamento ecológico-ambientalista podem fazer em seu interior dizem respeito ao próprio estabelecimento das premissas sociais de que partem. O mundo teórico é sempre aberto ao acerto de contas com o passado tradicional, que frequentemente procura cristalizar seus medos e preconceitos.

Argum., Vitória, v. 10, n. 2, p. 161-173, maio/ago. 2018. 


\section{REFERÊNCIAS}

FOLADORI, G. Metodología materialista para el análisis social. Montevideo: Extensión de la Universidad de la Republica, 1990. (Cuaderno de Extensión, n. 2).

FOLADORI, G. Una tipologia del pensamiento ambientalista. In: FOLADORE, Guillermo; PIERRI, Naína (Orgs.). Sustentabilidad? Desacuerdos sobre el desarollo sustentable. México: Universidade Autônoma de Zacatecas, Miguel Angel Porrúa, 2005.

FOSTER, J. B. A ecologia de Marx: materialismo e natureza. Rio de Janeiro: Civilização Brasileira, 2005 .

GALEANO, E. Quatro frases que aumentam o nariz do Pinóquio. Outras Mídias, São Paulo, 17 maio 2011. Disponível em:

<https://outraspalavras.net/outrasmidias/uncategorized/eduardo-galeano-aponta-quatromentiras-sobre-ambiente/>. Acesso em: 30 mar. 2018.

MARQUES, L. Capitalismo e colapso ambiental. Campinas: Unicamp, 2015.

MARX, K. Contribuição à crítica da economia política. São Paulo: Expressão Popular, 2008.

MARX, K.; ENGELS, F. A ideologia alemã. São Paulo: Expressão Popular, 2009.

MÉSZÁROS, I. Para além do capital. São Paulo: Boitempo, 2011.

NETTO, J. P. Introdução ao estudo do método de Marx. São Paulo: Expressão Popular, 2011.

ODUM, E. P. Fundamentos de Ecologia. São Paulo: Fundação Calouste Gulbenkian, 2001.

PONTING, C. Uma história verde do mundo. Rio de Janeiro: Civilização Brasileira, 1995. 